\title{
INFLUENCE OF FABRIC PARAMETERS ON THERMAL COMFORT PERFORMANCE OF DOUBLE LAYER KNITTED INTERLOCK FABRICS
}

\author{
Ali Afzal, Sheraz Ahmad *, Abher Rasheed, Faheem Ahmad, Fatima Iftikhar, Yasir Nawab \\ Faculty of Engineering \& Technology, National Textile University, Faisalabad-37610, Pakistan \\ Office address: Department of Materials \& Testing, Faculty of Engineering \& Technology, \\ National Textile University, Sheikhupura Road, Faisalabad-37610, Pakistan \\ Email address: itsadeelnaz@hotmail.com
}

\begin{abstract}
:
The aim of this study was to analyse the effects of various fabric parameters on the thermal resistance, thermal conductivity, thermal transmittance, thermal absorptivity and thermal insulation of polyester/cotton double layer knitted interlock fabrics. It was found that by increasing fibre content with higher specific heat increases the thermal insulation while decreases the thermal transmittance and absorptivity of the fabric. It was concluded that double layer knitted fabrics developed with higher specific heat fibres, coarser yarn linear densities, higher knitting loop length and fabric thickness could be adequately used for winter clothing purposes.
\end{abstract}

\section{Keywords:}

Thermal comfort, Double layer interlock knitted fabric, Thermal resistance, Cotton/Polyester

\section{Introduction}

The primary needs of human being include textiles as a major commodity. It comprises all the items used to protect the body from external environment. Textiles are used to cover as well as protect the body. When the external climatic conditions outmatch the body requirements, some specific fabrics are used to provide the optimum body demands for better comfort feelings. Comfort can be defined as "a pleasant state of psychological, physiological and physical harmony between a human being and the environment" [1]. Clothing plays a vital role in thermoregulatory process as it alters heat loss from the skin and also changes the moisture loss from skin [2] .

Heat transfer phenomenon through textiles is governed by various mechanisms including conduction and convection. The dry heat is transferred from the skin when textile materials get in direct physical contact with skin surface through conduction mechanism, while wet heat is transferred via convection mechanism with the help of moisture on the skin surface through the textile layer. A number of studies have been performed on both the mechanisms using different measurement techniques, modelling as well as materials to describe the effect of various parameters on the heat transfer abilities of the textile structures [3-7] . Different researchers investigated the effect of fibre, yarn and fabric properties on the thermal comfort performance of different fabrics [8-12] . Cimilli et. al. [8] investigated the effect of material type used for thermal comfort properties of plain jersey socks by modal, micromodal, bamboo, soybean, chitosan, viscose and cotton fibres. The results obtained suggested that there was statistical significant difference between the fibre type and the thermal resistance of fabrics. Schneider et al. [9] investigated the thermal conductivity of different fibres under moist conditions. Wan et al. [10], Schacher et al. [11] and
Ramakrishnan et al. [12] explained the effect of fibre fineness on thermal resistance of fabrics. According to them, the microdenier fibre gives low thermal conductivity and higher thermal resistance. Oglakcioglu et al. [13] studied the thermal comfort properties of $1 \times 1$ rib knit fabrics with different fibre blend ratios of cotton and angora fibre.

Pac et al. [14] studied the effect of fibre morphology, yarn and fabric structure on thermal comfort properties of fabric. Ozdil et al. [15] investigated the effect of different yarn parameters on thermal comfort of $1 \times 1$ rib knitted fabric. They explained that by decreasing count and yarn twist, the thermal resistance increases while moisture vapour permeability decreases. Majumdar et al. [16] found that by the use of finer yarn for knitted fabric formation of plain, rib and interlock structures by blend of bamboo and cotton fibres, the thermal conductivity of fabric reduces.

Khoddami et al. [17] explained that by the use of hollow fibre, the fabric thickness increases which increases the thermal resistance of the fabric. Greyson [18] , Havenith [19] and [20] presented their findings that heat resistance increases by increasing the air entrapped in the fabric as well as fabric thickness. Ucar and Yilmaz [21] have worked on thermal insulation properties of different rib structures made from cotton. Oglakcioglu and Marmarali [22] have studied the thermal comfort properties of different knitting structures. The structures under considerations were single jersey, interlock and $1 \times 1$ rib constructions with polyester and cotton fibres. They explained that interlock structure in both fibre types provide the higher thermal resistance due to more thickness of fabric.

Afzal et al. [7] studied the thermal resistance properties of interlock knitted fabrics. They reported that fibre type has a 
statistical significant influence on the thermal resistance of the interlock knitted fabrics. It was reported that fabric construction parameters directly affect the air permeability of interlock knitted fabrics [23] .

It is observed that no study has been made on the influence of fibre, yarn and fabric properties on thermal comfort of the double layer knitted fabrics. The objective of this study is to determine the effect of fibre type, composition, yarn and fabric properties on the thermal comfort performance of the double layer interlock knitted fabrics.

\section{Experimental}

\subsection{Yarn Production}

Carded ring spun yarns of linear densities 29 tex and 24 tex with polyester/cotton content percentage varying from 40/60 to $65 / 35$ were used for knitting double layer interlock knitted fabric structures. The properties of the yarns are shown in table 1.

The yarns were produced with same raw materials on the same production machinery settings. The twist multiplier for each count of different blend ratios was kept the same, that is, 3.45 and 3.47 for 29 tex and 24 tex, respectively.

\subsection{Fabric Production}

The double layer interlock knitted fabric samples were produced with three different tightness levels (slack, medium and tight) constructing loop lengths of $3.68 \pm 0.03 \mathrm{~mm}, 3.38 \pm 0.01 \mathrm{~mm}$ and $3.33 \pm 0.03 \mathrm{~mm}$, respectively. The change in fabric structure with different tightness factors is evident from Figure 1. Two sets of samples were produced classified on the basis of comparative higher polyester content in each layer of knitted fabric. In the first set, the polyester content percentage was comparatively higher in inside layer while in second set polyester content percentage was comparatively higher in outside layer. All the samples were fabricated on 18 guage Jacquard interlock circular knitting machine with 30 inches diameter, 1728 total needle count and a positive yarn feeding system. The individual samples fabricated for this study were 36 in number (table 2). Each individual sample had five replicates constituting total 180 specimens tested for this study.

\subsection{Fabric Processing}

The knitted samples were scoured, bleached and dyed with a liquid ratio of $7: 1$ before testing to obtain the actual working performance of the fabrics. Fabrics were dyed with disperse as well as reactive dye for polyester and cotton content dyeing to obtain olive green shade, respectively. Fabric dyeing was

Table 1. Properties of the yarns

\begin{tabular}{|c|c|c|c|c|c|c|}
\hline \multirow{2}{*}{ Parameter } & \multicolumn{4}{|c|}{ Mean Values } \\
\cline { 2 - 7 } & \multicolumn{3}{|c|}{29.21 tex } & \multicolumn{4}{c|}{241 tex } \\
\hline PES:CO (\%) & $40: 60$ & $52: 48$ & $65: 35$ & $40: 60$ & $52: 48$ & $65: 35$ \\
\hline Actual Count (tex) & 29.23 & 29.19 & 29.25 & 24.40 & 24.42 & 24.39 \\
\hline Evenness U\% & 10.18 & 9.65 & 9.39 & 10.87 & 10.24 & 9.88 \\
\hline Thin Place (-50\%)/km & 0 & 0 & 0 & 0 & 0 & 0 \\
\hline Thick Places (+50\%)/km & 65 & 47 & 42 & 108 & 92 & 88 \\
\hline Neps (+200\%)/km & 92 & 76 & 72 & 181 & 161 & 147 \\
\hline Hairiness & 7.81 & 7.26 & 7.02 & 7.19 & 7.01 & 6.78 \\
\hline Tenacity (cN tex ${ }^{-1}$ ) & 18.04 & 20.60 & 25.71 & 17.27 & 20.35 & 25.68 \\
\hline Breaking Elongation (\%) & 6.42 & 7.57 & 8.94 & 5.81 & 7.41 & 8.66 \\
\hline
\end{tabular}
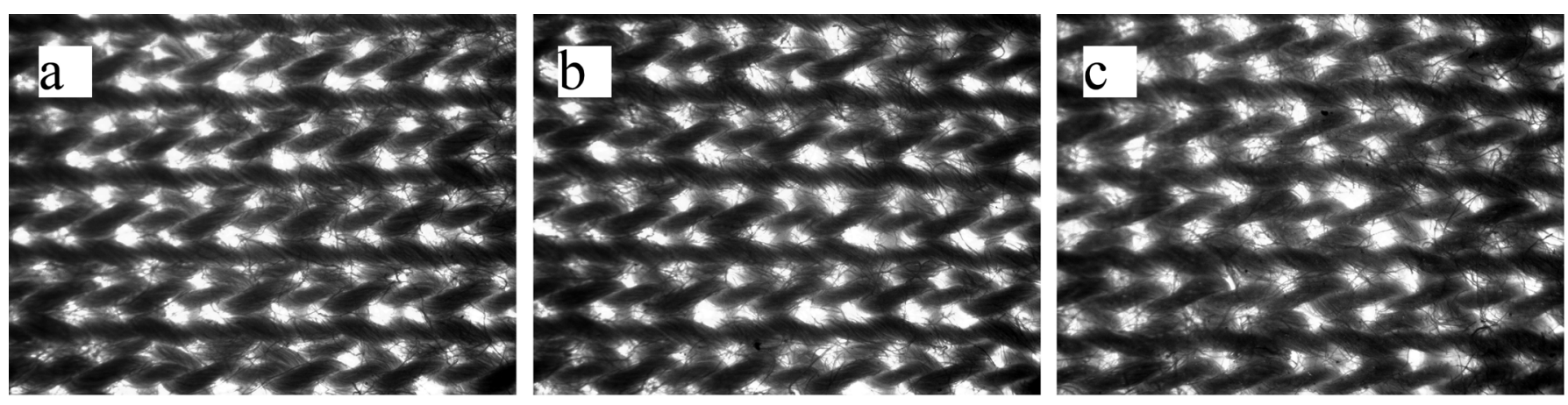

Figure 1: Fabric structures with different tightness factor $(K)(a) K=16.24$ (b) $K=16.04$ (c) $K=14.73$ 
Table 2: Fabric constructions used for the study

\begin{tabular}{|c|c|c|c|c|c|c|c|c|}
\hline $\begin{array}{l}\text { Sr. } \\
\text { No. }\end{array}$ & $\begin{array}{c}\text { Cotton } \\
\text { Content } \\
\text { Inside (\%) }\end{array}$ & $\begin{array}{l}\text { Cotton } \\
\text { Content } \\
\text { Outside } \\
(\%)\end{array}$ & $\begin{array}{c}\text { Yarn Linear } \\
\text { Density } \\
\text { (tex) }\end{array}$ & $\begin{array}{l}\text { Loop } \\
\text { Length } \\
(\mathrm{mm})\end{array}$ & $\begin{array}{c}\text { Tightness } \\
\text { Factor } \\
(\sqrt{\text { tex }}) / \mathrm{cm})\end{array}$ & $\begin{array}{c}\text { Fabric } \\
\text { Thickness } \\
(\mathrm{mm})\end{array}$ & $\begin{array}{c}\text { Areal } \\
\text { Density }(\mathrm{g} / \\
\left.\mathrm{m}^{2}\right)\end{array}$ & $\begin{array}{c}\text { Fabric } \\
\text { volume } \\
\text { density } \\
\left(\mathrm{Kg} / \mathrm{m}^{3}\right)\end{array}$ \\
\hline 1 & 35 & 48 & 24.4 & 3.32 & 14.88 & 1.18 & 393.1 & 333.1 \\
\hline 2 & 35 & 48 & 24.4 & 3.37 & 14.66 & 1.18 & 378.5 & 319.7 \\
\hline 3 & 35 & 48 & 24.4 & 3.70 & 13.35 & 1.20 & 356.5 & 297.1 \\
\hline 4 & 35 & 48 & 29.2 & 3.30 & 16.38 & 1.28 & 488.1 & 381.3 \\
\hline 5 & 35 & 48 & 29.2 & 3.38 & 15.99 & 1.26 & 462.7 & 367.2 \\
\hline 6 & 35 & 48 & 29.2 & 3.66 & 14.77 & 1.24 & 403.6 & 324.4 \\
\hline 7 & 35 & 60 & 24.4 & 3.36 & 14.70 & 1.21 & 392.2 & 323.6 \\
\hline 8 & 35 & 60 & 24.4 & 3.37 & 14.66 & 1.19 & 372.1 & 312.2 \\
\hline 9 & 35 & 60 & 24.4 & 3.65 & 13.53 & 1.17 & 331.1 & 283.5 \\
\hline 10 & 35 & 60 & 29.2 & 3.33 & 16.24 & 1.27 & 470.9 & 371.4 \\
\hline 11 & 35 & 60 & 29.2 & 3.37 & 16.04 & 1.28 & 453.0 & 355.0 \\
\hline 12 & 35 & 60 & 29.2 & 3.67 & 14.73 & 1.24 & 395.5 & 320.0 \\
\hline 13 & 48 & 35 & 24.4 & 3.32 & 14.88 & 1.18 & 393.1 & 333.1 \\
\hline 14 & 48 & 35 & 24.4 & 3.37 & 14.66 & 1.18 & 378.5 & 319.7 \\
\hline 15 & 48 & 35 & 24.4 & 3.70 & 13.35 & 1.20 & 356.5 & 297.1 \\
\hline 16 & 48 & 35 & 29.2 & 3.30 & 16.38 & 1.28 & 488.1 & 381.3 \\
\hline 17 & 48 & 35 & 29.2 & 3.38 & 15.99 & 1.26 & 462.7 & 367.2 \\
\hline 18 & 48 & 35 & 29.2 & 3.66 & 14.77 & 1.24 & 403.6 & 324.4 \\
\hline 19 & 48 & 60 & 24.4 & 3.32 & 14.88 & 1.19 & 371.4 & 311.6 \\
\hline 20 & 48 & 60 & 24.4 & 3.39 & 14.57 & 1.20 & 352.2 & 293.5 \\
\hline 21 & 48 & 60 & 24.4 & 3.70 & 13.35 & 1.18 & 316.5 & 269.1 \\
\hline 22 & 48 & 60 & 29.2 & 3.35 & 16.13 & 1.28 & 464.6 & 363.0 \\
\hline 23 & 48 & 60 & 29.2 & 3.39 & 15.94 & 1.30 & 449.5 & 346.8 \\
\hline 24 & 48 & 60 & 29.2 & 3.71 & 14.57 & 1.30 & 405.5 & 311.0 \\
\hline 25 & 60 & 35 & 24.4 & 3.36 & 14.70 & 1.21 & 392.2 & 323.6 \\
\hline 26 & 60 & 35 & 24.4 & 3.37 & 14.66 & 1.19 & 372.1 & 312.2 \\
\hline 27 & 60 & 35 & 24.4 & 3.65 & 13.53 & 1.17 & 331.1 & 283.5 \\
\hline 28 & 60 & 35 & 29.2 & 3.33 & 16.24 & 1.27 & 470.9 & 371.4 \\
\hline 29 & 60 & 35 & 29.2 & 3.37 & 16.04 & 1.28 & 453.0 & 355.0 \\
\hline 30 & 60 & 35 & 29.2 & 3.67 & 14.73 & 1.24 & 395.5 & 320.0 \\
\hline 31 & 60 & 48 & 24.4 & 3.32 & 14.88 & 1.19 & 371.4 & 311.6 \\
\hline 32 & 60 & 48 & 24.4 & 3.39 & 14.57 & 1.20 & 352.2 & 293.5 \\
\hline 33 & 60 & 48 & 24.4 & 3.70 & 13.35 & 1.18 & 316.5 & 269.1 \\
\hline 34 & 60 & 48 & 29.2 & 3.35 & 16.13 & 1.28 & 464.6 & 363.0 \\
\hline 35 & 60 & 48 & 29.2 & 3.39 & 15.94 & 1.30 & 449.5 & 346.8 \\
\hline 36 & 60 & 48 & 29.2 & 3.71 & 14.57 & 1.30 & 405.5 & 311.0 \\
\hline
\end{tabular}

followed by finishing for fabric stabilization. The fabric was stretched dry at 32 inch and compacted at 32 inch at a speed of $20-25 \mathrm{~m} / \mathrm{min}$ and temperature of $100-110^{\circ} \mathrm{C}$.

\subsection{Fabric Testing}

The samples were preconditioned in a hot-oven at standard conditions followed by conditioning according to ASTM D 1776 [24] in a standard atmosphere of $65 \pm 2 \%$ relative humidity and $20 \pm 2^{\circ} \mathrm{C}$ temperature. The thermal resistance testing was performed according to ISO 11092:1993 [25] on SDL Atlas M259B sweating guarded hotplate [26] . This instrument is also referred as a skin model used to stimulate the mass and heat transfer process which occur next to the skin surface. The standard sample was placed on the thermal plate enclosed in a controlled environment. The samples were tested in standard conditions for the thermal resistance which were $65 \pm 3 \% \mathrm{R} . \mathrm{H}$, $20 \pm 0.1^{\circ} \mathrm{C}$ air temperature, $1.00 \pm 0.05 \mathrm{~m} / \mathrm{s}$ air speed, $35 \pm 0.1^{\circ} \mathrm{C}$ 
thermal guard temperature and $35 \pm 0.1^{\circ} \mathrm{C}$ measuring unit temperature. The results obtained for thermal resistance of the fabric had the units of $m^{2} \mathrm{~K} / \mathrm{W}$.

\section{Results and Discussion}

The effects of different fabric parameters on thermal comfort performance were analysed statistically using Minitab $®$ statistical tool. The correlation analysis of different fabric properties with thermal resistance of the double layer knitted fabric is given in table 3 .

It is evident from the correlation analysis that cotton content percentage in both layers of the fabric was found statistically significant $(p$-value $<0.05)$ with a positive Pearson correlation coefficient. The highest positive Pearson correlation was found for cotton content percentage in both layers followed by loop length and fabric thickness. The fabric areal density had negative Pearson correlation coefficient value.

The effects of different parameters on thermal performance of the double layer fabric were analysed keeping all other parameters constant at their middle level values. The middle level values of the parameters are cotton content percentage outside at $47.5 \%$, cotton content percentage inside at $47.5 \%$, yarn linear density at $26.82 \mathrm{tex}$, loop length at $3.503 \mathrm{~mm}$, fabric thickness at $1.23 \mathrm{~mm}$ and fabric areal density at $402.1 \mathrm{~g} / \mathrm{m}^{2}$.

\subsection{Effect of Cotton Content Percentage Inside and Outside on Thermal Performance}

It is evident from Figure 2 that cotton content percentage is directly proportional to thermal resistance of the fabric. As cotton content percentage increases in inside layer, the thermal resistance also increases proportionally. Furthermore, the same relationship of thermal resistance was observed with the cotton content percentage outside. The specific heat of the cotton fibre is relatively higher than polyester fibre [27] , therefore as cotton fibre content percentage increase in any layer also increases the specific heat of the overall fabric due to which higher amount of energy is required to raise the temperature and transfer the heat on the other side of the fabric. As a result of increase in fabric specific heat, the thermal resistance increases correspondingly.

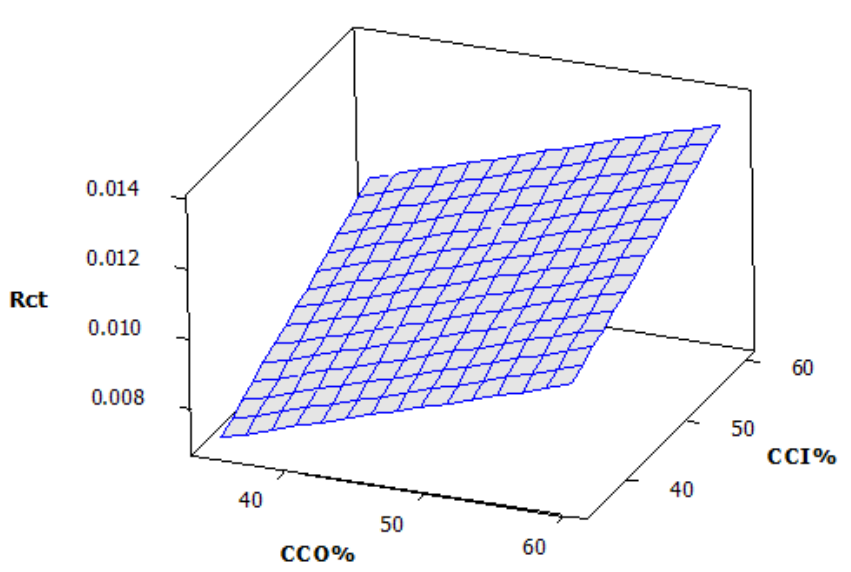

Figure 2: Surface plot of thermal resistance vs cotton content percentage inside and outside at constant middle level values of other variables

Thermal conductivity of the cotton fibre is higher than polyester fibre [27] . It has been reported that thermal conductivity of fabric depends much more on the air entrapped within it than on fibre conductivity [27] . As cotton fibre has convolutions and more crimpy yarn structure, resultantly the air entrapping efficiency is better than polyester fibre yarn. Therefore, the overall thermal conductivity of the fabric decreases by the increase in cotton content percentage in the fabric layers.

Thermal insulation is directly proportional to thermal resistance and inversely proportional to thermal transmittance. Thermal insulation is a property which is highly related to technical performance of textiles. Therefore, as the thermal resistance increases, the thermal insulation increases along with. Therefore, as the thermal insulation of the fabric increases by the increase in cotton content percentage, the thermal transmittance decreases.

Thermal absorptivity is the objective measurement of warm cool feeling of the fabric. Fabrics with a lower thermal absorptivity value have warm feeling and vice versa. It is observed that the thermal absorptivity value increases by decreasing cotton content percentage in an inner layer of the fabric. That was due to a higher thermal conductivity of the polyester fibre. The thermal absorptivity was calculated by using specific heat of the inside layer of the fabric which would be in contact with the body during use.

Table 3: Correlation between thermal resistance and fabric properties

\begin{tabular}{|c|c|c|}
\hline Parameter & Pearson correlation & P-value \\
\hline Cotton content outside percentage & 0.285 & $0.000^{*}$ \\
\hline Cotton content inside percentage & 0.285 & $0.000^{*}$ \\
\hline Yarn linear density (tex) & 0.070 & $0.354^{* *}$ \\
\hline Loop length (mm) & 0.253 & $0.001^{*}$ \\
\hline Fabric thickness (mm) & 0.068 & $0.368^{* *}$ \\
\hline Areal density $\left(\mathrm{g} \mathrm{m}^{-2}\right)$ & -0.222 & $0.003^{*}$ \\
\hline \multicolumn{3}{|c|}{$\begin{array}{l}{ }^{*} \text { Correlation is statistically significant at } 0.01 \text { level }(99 \% \text { confidence }) \\
{ }^{* *} \text { Correlation is statistically insignificant at } 0.05 \text { level }(95 \% \text { confidence })\end{array}$} \\
\hline
\end{tabular}




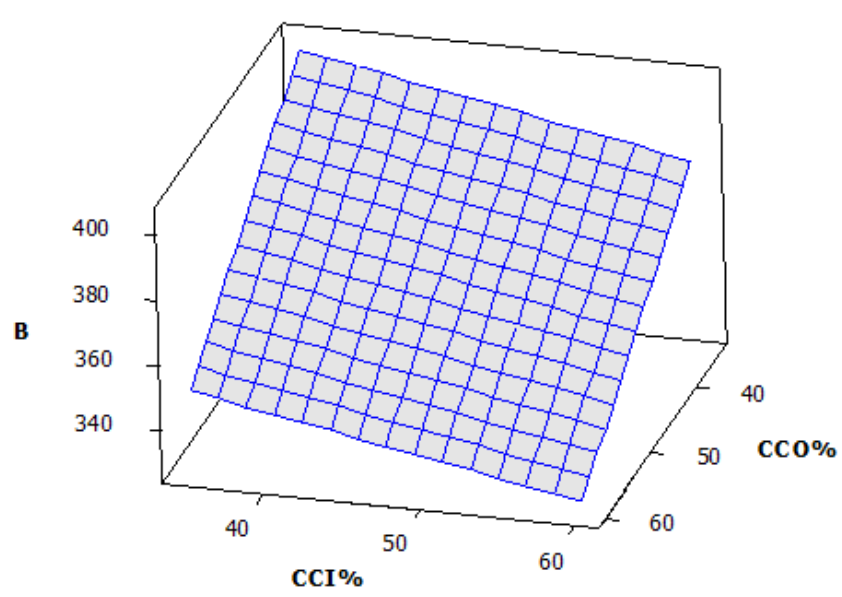

Figure 3: Surface plot of thermal absorptivity vs cotton content percentage inside and outside at constant middle level values of other variables

It is evident from Figure 3 that the thermal absorptivity of inside layer was also affected by cotton content percentage of outside layer, but this effect was found very less as compared with inside layer. At the interlacement points of two layers, the outside layer yarn comes in contact with an inside layer yarn and hence changes the total specific heat and conductivity of the fibres at that point. This change in specific heat and conductivity at interlacement point causes the influence of outside layer fibre content on the thermal absorptivity of inside layer of the double layer fabric.

\subsection{Effect of Yarn Linear Density and Fabric Thickness on Thermal Performance}

It was observed that yarn linear density and fabric thickness are in direct proportion with a thermal resistance of the fabric as shown in Figure 4. When the fabric thickness increases, the air gaps in the fabric structure increases. As the air is a good thermal insulator, therefore by increasing fabric thickness the thermal resistance increases as well. In the same consideration, as yarn linear density (tex) increases the fabric thickness also increases due to higher yarn diameter and ultimately the resultant fabric thickness. Hence, increases in the thermal resistance of the fabric.

As thermal resistance increases due to increase in yarn linear density and fabric thickness, the thermal insulation increases as well. The effect of yarn linear density and fabric thickness on thermal conductivity and thermal absorptivity was observed very much similarly as shown in Figure 5.

It was observed that thermal conductivity and absorptivity decreases sharply by increase in yarn linear density. The effect of fabric thickness on thermal conductivity and absorptivity is in direct proportion with each other. This is explained on the fact that by increase in fabric thickness, the fibre weight per unit area increases. This increase in fibrous material, having a higher thermal conductivity than air, increases their contact points with each other and influences the convenient heat flow across the fabric layers.

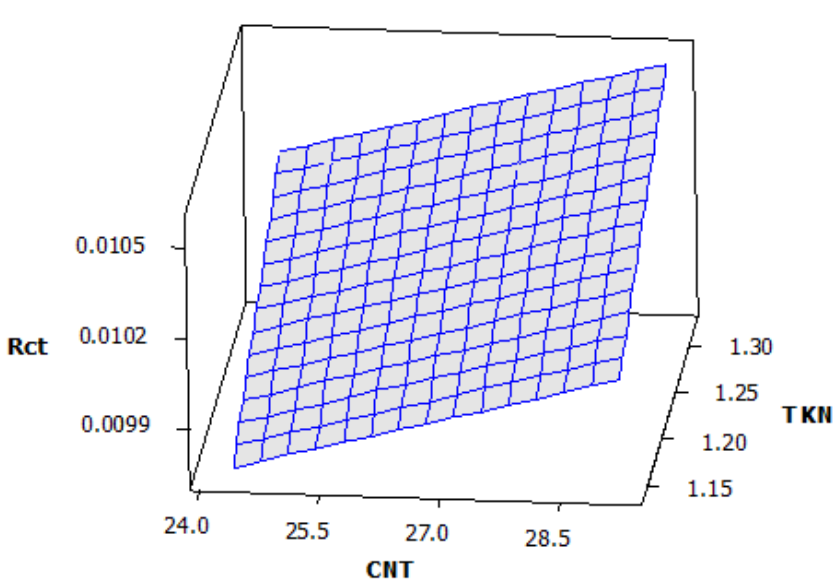

Figure 4: Surface plot of thermal resistance vs yarn linear density and fabric thickness at constant middle level values of other variables

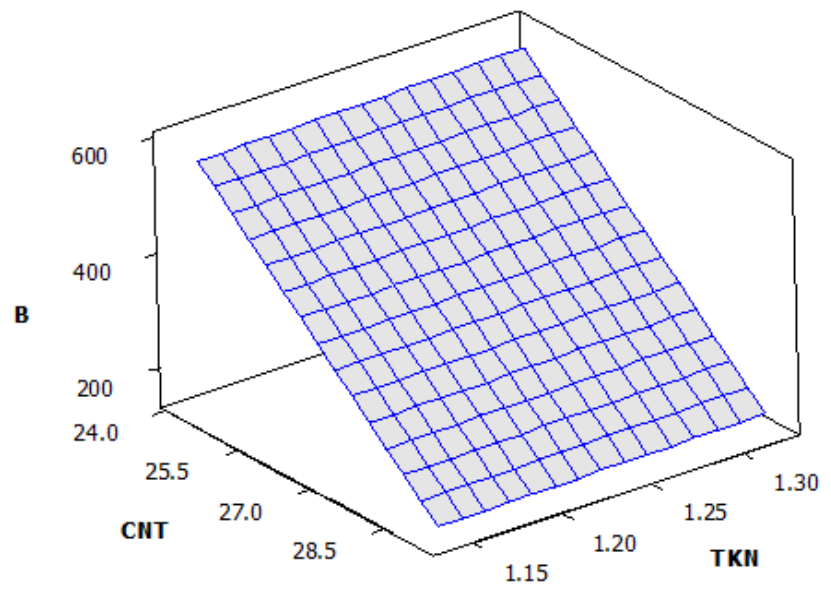

Figure 5: Surface plot of thermal absorptivity vs yarn linear density and fabric thickness at constant middle level values of other variables

\subsection{Effect of Loop Length and Areal Density on Thermal Performance}

It is evident from Figure 6 that thermal resistance decreases as the areal density increases proportionally. The loop length was found in direct proportion with thermal resistance of the fabric. The thermal resistance increases by increase in loop length of the fabric. This is due to increase in air gaps generated by increase in loop length of the fabric. As air is a good thermal insulator, therefore increase in air gaps results in improved thermal resistance.

The effects of thermal absorptivity and conductivity on loop length and areal density were found similar as shown in Figure 7. As the areal density of the fabric increases, the thermal conductivity also increases due to increase in conductivity of the overall structure by increase in contact points and fibrous material. This leads to a decrease in thermal resistance in same accord.

On the contrary, it is evident that the effect of loop length on the thermal conductivity and absorptivity was in direct proportion. As discussed before that thermal resistance was also increases by an increase in loop length. The increase in 
thermal resistance and thermal conductivity at the same time by an increase in loop length is explained due to decrease in fabric thickness proportionally and change in pore structure.

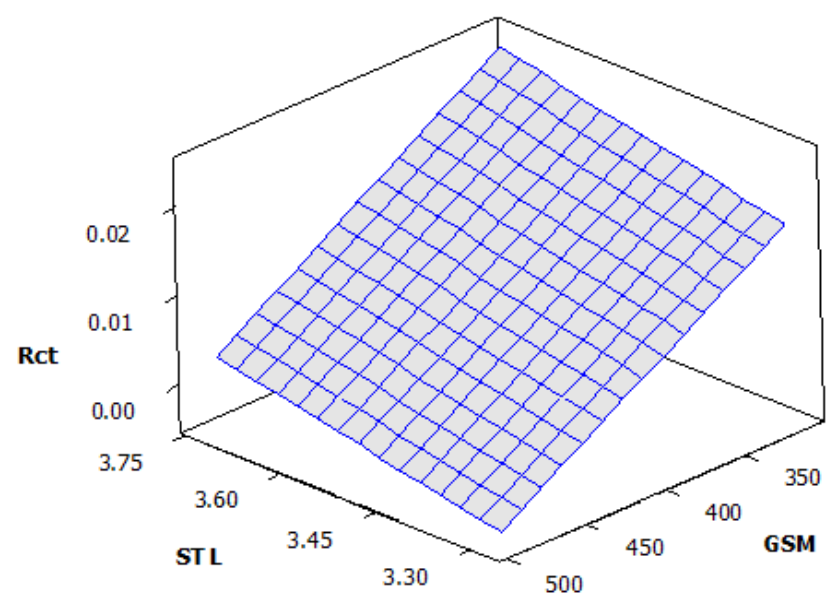

Figure 6: Surface plot of thermal resistance vs loop length and fabric areal density at constant middle level values of other variables

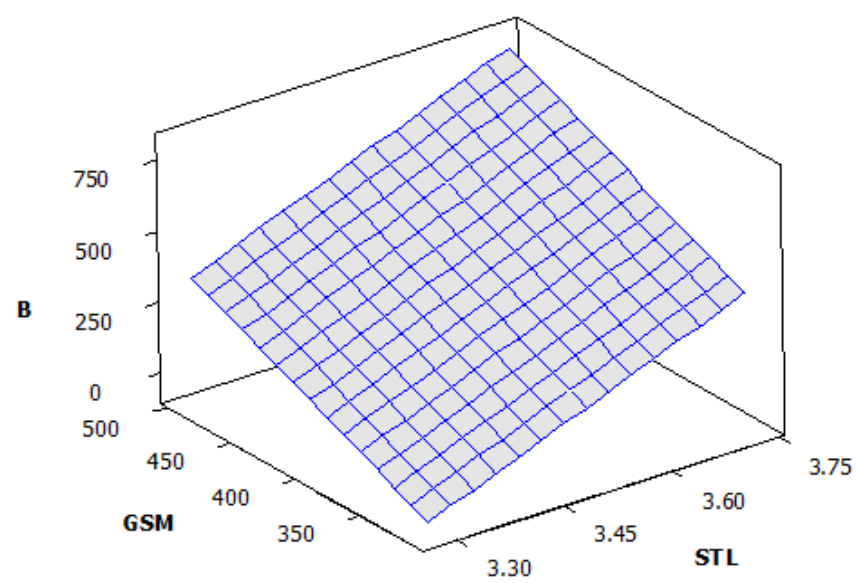

Figure 7: Surface plot of thermal absorptivity vs loop length and fabric areal density at constant middle level values of other variables

\section{Conclusion}

It is concluded that the thermal resistance of double layer fabric depends upon the fibre type and blend percentage used in each fabric layer. The dependence of thermal insulation on fibre type is governed by the specific heat of the fibre. The thermal resistance of the fabric increases by increasing the percentage of fibre having higher specific heat. It was also concluded that the yarn linear density, loop length and fabric thickness are in direct proportion with thermal insulation of the fabric. The fabric areal density was found in an inverse proportion to the thermal resistance of double layer fabric. The thermal absorptivity of the fabric decreases by decreasing fabric areal density and by increasing cotton content, yarn linear density and fabric thickness. Therefore, double layer fabric having higher yarn linear density (tex), fabric thickness and loop length with lower fabric areal density could be adequately used for winter clothing.

\section{Nomenclature}

$\mathrm{R}_{\mathrm{ct}}=$ Thermal resistance $\left[\mathrm{m}^{2} \mathrm{KW}^{-1}\right]$

$\mathrm{B}=$ Thermal absorptivity $\left[\mathrm{Ws}^{1 / 2} \mathrm{~m}^{-2} \mathrm{~K}^{-1}\right]$

$\mathrm{CCO}=$ Cotton content percentage outside [\%]

$\mathrm{CCl}=$ Cotton content percentage inside $[\%]$

CNT = Yarn linear density [tex]

$\mathrm{STL}=$ Loop length $[\mathrm{mm}]$

TKN = Fabric thickness $[\mathrm{mm}]$

$\mathrm{GSM}=$ Fabric areal density $\left[\mathrm{gm}^{-2}\right]$

\section{Refrences}

[1] Slater, K. Human Comfort. C. C. Thomas, Springfield, Illinois, 1985

[2] Saville, B. P. Comfort. In: Physical Testing of Textiles. Woodhead Publishing Ltd., Cambridge, England, 1999, pp. 209-243

[3] Ciesielska-Wrobel, I., De Mey, G. and Van Langenhove, L. Dry heat transfer from the skin surface into textiles: subjective and objective measurement of thermal haptic perception of textiles - preliminary studies. In: The Journal of The Textile Institute, 2015, pp. 1-11

[4] Havenith, G. Individualized model of human thermoregulation for the simulation of heat stress response. 2001

[5] Havenith, G., Holmér, I. and Parsons, K. Personal factors in thermal comfort assessment: clothing properties and metabolic heat production. In: Energy and Buildings, 2002, vol. 34, issue 6, pp. 581-591

[6] Fiala, D., Havenith, G., Bröde, P., Kampmann, B. and Jendritzky, G. UTCI-Fiala multi-node model of human heat transfer and temperature regulation. In: International Journal of Biometeorology, 2012, vol. 56, issue 3, pp. 429441

[7] Afzal, A., Hussain, T., Mohsin, M., Rasheed, A. and Ahmad, $S$. Statistical models for predicting the thermal resistance of polyester/cotton blended interlock knitted fabrics. In: International Journal of Thermal Sciences, 2014, vol. 85, pp. $40-46$

[8] Cimilli, S., Nergis, B. U. and Candan, C. A comparative study of some comfort related properties of socks of different fiber types. In: Textile Research Journal, 2010, vol. 80 , issue 10, pp. 948-957

[9] Schneider, A. M., Hoschke, B. N. and Goldsmid, H. J. Heat transfer through moist fabrics. In: Textile Research Journal, 1992, vol. 62, issue 2, pp. 61-66

[10] Wan, X., Fan, J. and Wu, H. Measurement of thermal radiation properties of penguin down and other fibrous materials using FTIR. In: Polymer Testing, 2009, vol. 28, pp. 673-679

[11] Schacher, L., Adolphe, D. C. and Drean, J. Y. Comparison between thermal insulation and thermal properties of classical and microfibres polyester fabrics. In: International Journal of Clothing Science and Technology, 2000, vol. 12, issue 2, pp. 84-95

[12] Ramakrishnan, B., Durai, B. and Mukhopadhyay, S. An investigation into the properties of knitted fabrics made from viscose microfibres. In: Journal of Textile and Apparel, Technology and Management, 2009, vol. 6, pp. 1-9 
[13] Oglakcioglu, N., Celik, P., Ute, T. B., Marmarali, A. and Kadoglu, $H$. Thermal comfort properties of angora rabbit/ cotton fiber blended knitted fabrics. In: Textile Research Journal, 2009, vol. 79, issue 10, pp. 888-894

[14] Pac, M. J., Bueno, M. A. and Renner, M. Warm-cool feeling relative to tribological properties of fabrics. In: Textile Research Journal, 2001, vol. 71, issue 9, pp. 806-812

[15] Ozdil, N., Marmarali, A. and Kretzschmar, S. D. Effect of yarn properties on thermal comfort of knitted fabrics. In: International Journal of Thermal Sciences, 2007, vol. 46, pp. 1318-1322

[16] Majumdar, A., Mukhopadhyay, S. and Yadav, R. Thermal properties of knitted fabrics made from cotton and regenerated bamboo cellulosic fibers. In: International Journal of Thermal Sciences, 2010, vol. 49, pp. 2042-2048

[17] Khoddami, A., Carr, C. M. and Gong, R. H. Effect of hollow polyester fibres on mechanical properties of knitted wool polyester fabrics. In: Fibers and Polymers, 2009, vol. 10, issue 4, pp. 452-460

[18] Greyson, M. Encyclopedia of composite materials and components. Wiley \& Sons, USA, 1983

[19] Havenith, G. Interaction of clothing and thermoregulation. In: Exogenous Dermatology, 2002, vol. 1, issue 5, pp. 221 230
[20] Milenkovic, L., Skundric, P., Sokolovic, R. and Nikolic, T. Comfort properties of defence protective clothing. In: The Scientific Journal Facta Universitatis, 1999, vol. 1, issue 4, pp. 101-106

[21] Ucar, N. and Yilmaz, T. Thermal Properties of $1 \times 1,2 \times 2$ and $3 \times 3$ rib knit fabrics. In: Fibers and Textiles in Eastren Europe, 2004, vol. 12, issue 3, pp. 34-38

[22] Oglakcioglua, $N$. and Marmarali, A. Thermal comfort properties of some knitted structures. In: Fibers and Textiles in Eastern Europe, 2007, vol. 15, issue 5, pp. $94-96$

[23] Afzal, A., Hussain, T., Malik, M. H. and Javed, Z. Statistical model for predicting the air permeability of polyester/ cotton-blended interlock knitted fabrics. In: The Journal of The Textile Institute, 2014, vol. 105, issue 2, pp. 214-222

[24] ASTM D 1776. Standard practice for conditioning and testing textiles. ASTM International, 2004

[25] ISO 11092. Textile - Physiological effects - Measurement of thermal and water vapour resistance under steady state conditions (sweating guarded hotplate test). International Organization for Standardization, 2014

[26] Atlas M259B Sweating guarded hotplate instruction manual. SDL Atlas Inc., 2010

[27] Morton, W. E. and Hearle, J. W. S. Thermal properties. In: Physical Properties of Textile Fibers. Woodhead Publishing Ltd., Cambridge, England, 2008, pp. 168-177 